\title{
Earnings Implications of Person Years Lost Life Expectancy Among Canada's Aboriginal Peoples
}

\author{
Paul S. Maxim \\ Jerry P. White \\ Stephen Obeng Gyimah \\ Department of Sociology \\ University of Western Ontario \\ London, Ontario, Canada \\ Daniel Beavon \\ Department of Indian Affairs and Northern Development \\ Ottawa, Ontario, Canada
}

\begin{abstract}
Overall, Canada has one of the world's highest national life expectancies. This benefit is not shared by Canada's aboriginal population, however, which has a life expectancy approximately seven years less than the general population. The Aboriginal population also differs in that it has a higher fertility rate and higher mortality rates among infants and young adults. One of the consequences of the mortality differential is that the number of person years of lost life (PYLL) expectancy is large for the Aboriginal community in comparison to the general population. While several studies have focused on the causes of differential mortality, this study examines some of the socio-economic consequences of differences in PYLL. Examining wage labor income, for example, we determine that the PYLL differential translates into an expected wage and salary loss of approximately $\$ 1.56$ billion.
\end{abstract}

Key Words: Life expectancy, aboriginal population, PYLL, socio-economic characteristics 
Paul S. Maxim, Jerry P. White, Stephen O. Gyimah and Daniel Beavon

\section{Résumé}

Dans l'ensemble, l'espérance de vie au Canada est une des plus longues au monde. Cependant, la population autochtone du Canada ne partage pas cet avantage, son espérance de vie étant d'environ sept ans inférieure à celle de la population générale. La population autochtone se distingue aussi par le fait qu'elle a un taux de fertilité supérieur et un taux de mortalité supérieur chez les enfants et les jeunes adultes. En conséquence, l'espérance du nombre d'années potentielles de vie perdues (APVP) est considérable pour la communauté autochtone par rapport à la population générale. Alors qu'il existe déjà plusieurs études sur les causes de la différence du taux de mortalité, cette étude en examine certaines des conséquences socio-économiques. En examinant le revenu provenant d'un salaire par exemple, nous pouvons établir que la différence en APVP se traduit en une perte salariale prévue d'environ 1,56 million \$.

Mots-clés : espérance de vie, population autochtone, APVP, caractéristiques socio-économiques

\section{Introduction}

According to the OECD (1999), Canada ranks third among developed countries in life expectancy, behind Japan and Switzerland. This enviable situation does not hold, however, for Aboriginal people in Canada (Beavon and Cook, 2003) ${ }^{1}$ Canada's Aboriginal peoples have different demographic profiles than the general Canadian population along several dimensions. The Aboriginal population has proportionately more youth, a higher rate of population growth, and a much higher rate of mortality, particularly in the earlier years. Aboriginal peoples also have a markedly higher fertility rate than the Canadian population (Indian Affairs and Northern Development, 1997). In 1996 that rate was 69\% higher. There were 491 children under the age of five for every 1,000 Aboriginal women in 1996 in comparison to 290 children for every 1,000 women in the general population (Statistics Canada, 1998a).

The gap in life expectancy at birth between Aboriginal people and other Canadians has diminished in the past three decades, but remains close to seven years. The gap is even larger for people living on reserves. In 1990, the life expectancy of Aboriginal peoples living on reserves or First Nations communities was 62 years for men and 69.6 years for women. The corresponding figures for 
all other Canadians were 74.6 years for men and 80.9 years for women. An examination of age-specific mortality shows that the gap between Aboriginal and non Aboriginal populations is very wide between the 15 to 44 age range (Frideres, 1998: 180-81). While infant mortality rates have fallen from 28 to 11 per 1,000 live births between 1979 and1993, it remains nearly twice the national average (Indian and Northern Affairs Canada, 1997).

A recent study by Health Canada (1996) reports that mortality among registered Indians aged 1 to 4 years in 1993, was four times higher than the national rate. This study also suggests that, for registered Indians in 1993, crude death rates are 4.7 per 1,000 for women and 6.4 per 1,000 for men. The markedly different age structures of Aboriginal peoples and the general Canadian population make a direct comparison of crude rates misleading. Controlling for age structure, the overall age- standardized mortality rate among registered Indians is 10.8 per 1,000 population, but only 6.9 per 1,000 for the general Canadian population. Significant sex differences are also evident, with the age- standardized rate for registered Indian women being 10.0 per 1,000 whereas for men it is 11.5 per 1,000 population. Among all Canadians, the corresponding rates of mortality are 6.3 for women and 7.4 for men. While the mortality gap between genders decreased for the general Canadian population since the 1970s, it increased for the Aboriginal population between 1975 and 1980. Since then, it has stayed relatively stable.

This combination of a greater concentration and a higher rate of mortality among younger people suggests that Canada's Aboriginal populations suffer many more person years of lost life (PYLL) in comparison to the broader Canadian population. That is to say, Aboriginal peoples experience greater unfulfilled life expectancy. While most of the epidemiological and demographic research on person years lost life focusses on the causes of differential mortality, this study seeks to illustrate some consequences of that pattern of differential mortality . In particular, this study attempts to quantify the potential cost to the Aboriginal community in terms of lost income. This involves looking at lost productivity through income, and the lost recovery of costs that young people accrue while growing up from birth to labour force entry at eighteen years of age.

\section{Review of Literature}

Registered Indians not only have higher overall rates of mortality, but, they also have higher rates of mortality among the younger members of that population. The largest differential in age-specific mortality is to be found among children and infants. Among infants, most of the difference is due to post neonatal (beyond twenty-eight days) mortality. In 1997, the neonatal death rate was nearly 
twice the national neonatal death rate and the post neonatal death rate was nearly five times the national average (Statistics Canada, 1997). Epidemiologically, child mortality and post neonatal mortality are more sensitive to variations in lifestyle and socioeconomic conditions than variations in healthcare resources (Indian Affairs and Northern Development, 1999a: 11, 24). Lifestyle and socioeconomically related causes of death are also the primary determinants of mortality among older members of the population. The mortality pattern for Aboriginal peoples shows marked differences from the general population. In Canada, diseases of the circulatory system are the main cause of death with cancer, injuries and poisoning following in that order (Statistics Canada, 1998c). Among Registered Indians, the primary causes of mortality are injury and poisoning, diseases of the circulatory system, neoplasms (cancer), and diseases of the respiratory system (Indian Affairs and Northern Development, 1999a).

Registered Indians have higher rates of infectious diseases than other Canadians (Trovato 2001) however, it is not the rampant spread of such conditions that produce the large differences in excess mortality (Norris 1996; Bobet 1989; Boldt 1993). Registered Indians have higher rates of violent death than other Canadians (e.g., homicide, suicide, deathly fire and other accidents) (Royal Commission on Aboriginal Peoples,1995; Mao et al . 1992; Sinclair 1998; Kirmayer 1998) . They also have higher rates of deaths associated with the use of alcohol and other substances than the non Native population (Whitehead and Hayes 1998). Recent studies also indicate that Canadian Aboriginal Populations experience a greater inequality in mortality than other Aboriginal Peoples such as U.S. American Indians or New Zealand's Maori (Trovato 2001).

The same factors that produce high numbers of person years of lost life often result in variations in lifestyle and socioeconomic circumstances. That is to say, losses in the potential development of human capital have implications for labour force participation and earnings. Thus, we would argue, there is some reciprocity at both the individual and the community levels between cause of death and socioeconomic circumstances over the life course of families and communities.

Many studies have catalogued the difference between Aboriginal and non Aboriginal education attainment. In 1996, 54\% of the Aboriginal population did not have high school certificates while only $35 \%$ of the non Aboriginal population was in that position (Statistics Canada, 1998b). Labour force participation and unemployment levels differ for the populations as well. Some research conservatively estimates unemployment on reserves at nearly three times the national average (Indian Affairs and Northern Development, 1999a). Clatworthy et al. (1995) found mean income for workers of Aboriginal origin to be $\$ 17,367$ but they also found variation among the various Aboriginal groups. Non Status Indians had a mean income of $\$ 21,035$, registered Indians $\$ 15,791$, 
Métis, $\$ 18,467$ and Inuit, $\$ 15,690$. They conclude that, while the gap for those with full time/full year employment (40+ weeks) is smaller than those with other employment statuses, the earnings of registered Indians and Inuit were behind all other Aboriginal peoples and even further behind the Canadian labour force as a whole. In 1997, the social services dependency rate of First Nations was four times the Canadian average rate (Indian Affairs and Northern Development. 1999b).

Personal years of life lost (PYLL) is a concept that researchers have employed in a variety of instances to illustrate the impact of differential mortality rates. Developed in 1944 by Hersch, the concept has been valuable in a range of applications (Panush and Peritz, 1996). PYLL is useful because it allows for the calculation of lost life expectancy attributable to specific causes of death. It also places greater emphasis on deaths that occur at earlier, rather than later, ages. The application of PYLL analysis to Aboriginal peoples and First Nations communities provides researchers and those concerned with public policy with a unique indicator of some problems facing those communities. Over time, this type of analysis can also serve as a barometer for a variety of social, economic and health problems in the population.

\section{Using Personal Years of Life Lost}

Personal years of life lost is the number of years that an individual might have lived lacking a defined factor (e.g., cardiovascular disease or homicide). Premature mortality obviously has social and emotional implications, but it also has economic and productivity implications.

Researchers started to use PYLL extensively in the 1970s to investigate public health issues. For example, they examined extensively the costs associated with lost productivity due to premature death associated with heart and cerebrovascular diseases. That trend has continued and remains a major approach for studying the socioeconomic impact of disease. A Californian study using PYLL calculations, for example, suggests that cardiovascular related deaths result in more than 6.4 billion dollars in productivity losses (Fox et al., 1996).

The concept has also gained acceptance in criminology and ethnic studies with several studies of the African-American population (Rose, 1979). Throughout the 1980s and the 1990s, PYLL continued to be useful in quantifying losses due to exceptionally high rates of homicide among African-American males in US cities. These studies concluded that interpersonal violence was emerging as the primary cause of death for African-Americans in younger age brackets (MartinezSchnell and Waxwieler 1989). Furthermore, from an economic perspective, 
Paul S. Maxim, Jerry P. White, Stephen O. Gyimah and Daniel Beavon

violence-related mortality affects the African-American community disproportionately among those under the age of 65 (Ammons, 1997).

PYLL has applications in other contexts. Some studies have examined the relationship between income distribution and mortality (McIsaac and Wilkenson, 1997). These studies suggested a strong negative correlation between the share of income and PYLL from all causes of death among the poorer deciles of the population, and a strong positive correlation among the wealthier deciles. The PYLL approach to assessing the effects of differential mortality has been useful in less dramatic situations such as in the relationship between social class and mortality. Because it weights losses by age of death, PYLL can reveal patterns that other analytical approaches do not express as dramatically. In mortality differential studies relating to social class, the common approach is to construct standardized mortality ratios. When researchers extend these studies to include PYLL before age 75, however, the picture of what is the most important cause of death become much clearer (Beer et al., 1993).

\section{Personal Years of Life Lost: A Window on Problems}

What are we looking at when we measure the years of lost life in community? First, we are measuring loss of resources available to a community. Second, we are making a forecast of future difficulties that a community may face given those losses. Third, we are quantifying losses to a community in a way that can, over time, show the possible impact of policy changes.

Examining the life course from a community resources perspective, we can see that there are several distinct phases involved. The first phase involves dependency. At this stage, a community cares for its young by investing in them. In a real sense, young people are economic and social burdens on the community. During the second phase of the life course, young adults start to pay back that community investment through their economic productivity. As adults, they invest resources into the community by financially supporting and socializing the young. The third stage occurs when people are older and, again, the community is expected to provide some elements of support. Unlike investments in the very young, however, the resource flow is not unidirectional since the elderly also continue to make some social and economic contributions. Sometimes these contributions are in less economically tangible commodities such as when the community benefits from the knowledge and wisdom of the elderly. When a life is cut short in the teen years, the community does not see a return on its social and economic investment in that person. Ultimately, fewer resources are available for care of the elderly and for the nurturing, socializing and care of the young. In this way, PYLL is a gauge of a community's losses. 
Pre-labour force investment in young citizens is a substantial cost to a community. These costs include but are not limited to education, healthcare, and the family costs of nurturing the young person. These costs are born in different ways but are expressed in two primary forms of expenditure: public and private. The precise accounting of these different expenses is difficult but we have constructed some simple measures of these social costs.

\section{Data}

The data for this analysis are drawn from several sources. National mortality come from the $\mathrm{q}_{\mathrm{x}}$ column of Statistics Canada's (1995) estimated life table for 1990-1992.3 Statistics Canada supplied special mortality rate estimates for Registered Indians. Data relating to age-sex-specific population counts and estimated income for Registered Indians come from the Public Use Micro File (PUMF) on individuals based on the 1996 Census of Canada.

\section{Assumptions}

Life tables: The life tables used in this analysis are standard cross-sectional life tables, and are subject to the normal assumptions. The primary restriction is the assumption that the age-sex-specific rates of mortality will apply over the lifetimes of the individuals included in the analysis. Recent experience suggests that mortality rates are not stationary, however, and that life expectancies are generally increasing for both the Aboriginal and non Aboriginal populations in Canada.

Registered Indians: The target population for this study consists of those individuals who identified themselves as Registered Indians on the 1996 PUMF. Unfortunately, a substantial undercount of Registered Indians exists on the file because of underenumeration. The census also probably underestimates the number of infants (under 1-year of age) since we do not have a count of the total number of births for the year.

Income: The 1996 PUMF is also the source of age and sex-specific income estimates for Registered Indians and all Canadians. It provides two indicators of income: income due to wages and salaries, and total personal income. Both are self-reported, gross estimates provided by the census respondents. Mean income is evaluated for each five-year age group, including those persons with zero reported income. 
For this study, we decided to focus on the earnings of those people who are generally considered "labour market eligible." This includes only those between the ages of 20 and 64 . We considered including those between the ages of 15 and 19; however, the large proportion of individuals still in school is problematic. The assumption was made that had those who died before age 20 survived, their life time earnings will be equal to that of those at labour force entry age (20-24 years). The analysis excludes those 65 years of age and older. The reason for this exclusion is the high proportion of people 65 years and over whose primary income is due to pensions. Since some people outside the range 20-64 obviously have labour force earnings, the totals of the estimates provided are likely be conservative.

\section{Detailed Calculations}

\section{Estimating Excess Mortality}

Excess mortality was estimated and it consists of those people who died in a specific age interval because they were exposed to the First Nations mortality regime as opposed to the national mortality regime. The estimate is based on the difference between the expected proportion of deaths for each 5-year group multiplied by the estimated number of people within that interval.

\section{Estimating the PYLL}

On the basis of the 'excess mortality' and the 1996 Aboriginal life expectancy at birth for each sex (68.3 for males; 76 years for females), we estimated the PYLL. Since the data are aggregated, it is clear that not everyone would die either at the beginning or the end of the interval. We have assumed, therefore, that the deaths within a particular interval occur at the mid-point of the interval. To obtain an estimate of the total potential years of lost life for any five-year age group for a particular sex $(i-m)$, we used the following formula:

$$
\operatorname{PYLL}_{(i-m)}=\left(e_{0}-m\right) *\left(E D_{i-m}\right)_{\text {where, }}
$$

$e_{0}$ is the Aboriginal life expectancy for that sex;

$\boldsymbol{m}$ is the mid point of the age group under consideration; 
$E D_{i m}$ is the excess deaths for the age group.

Summing over all of the age intervals estimates the total number of potential years of lost life. We have not estimated values beyond the Aboriginal life expectancy for each sex.

\section{Estimating Lost 1ncome}

One objective of this study is to estimate the amount of lost income due to excess mortality in the Registered Indian population. To obtain this estimate, the average earnings for those alive within the interval is used as an estimate of potential lost income. Mean wage and salary income, and total personal income are used in the analysis. Once the mean income for the interval is estimated, an estimate of life time earnings and income for each for each age group is computed. The total life time wages and salaries and income lost are estimated by multiplying expected life time earnings by excess mortality. Two of the main assumptions behind this calculation are that the earnings of people within the interval are homogeneous and that death is instantaneous. That is, we have not discounted the earnings for any morbidity effects before death.

\section{Results}

The first step in this analysis is to estimate excess mortality resulting from of the Registered Indian population having a mortality regime different from the Canadian population at large. We can then estimate the value of that excess mortality in terms of lost income.

\section{Excess Mortality}

Excess mortality is the product of the difference between the mortality experience of Registered Indians and that of other Canadians. Figure 1 illustrates these across-group differences by plotting the logarithms of the age-specific mortality rates by age. Excess mortality for each category of age is summed to produce an estimate of the person years of lost life. In all age categories, Registered Indian men have higher rates of mortality than the average non-Aboriginal Canadian. The differences in mortality generally increase with age. The total estimated person years of lost life is 102,437 for men (Table 1). 
Figure 1. $Q x(x)$ Values by Population and Sex for Registered Indians in Canada

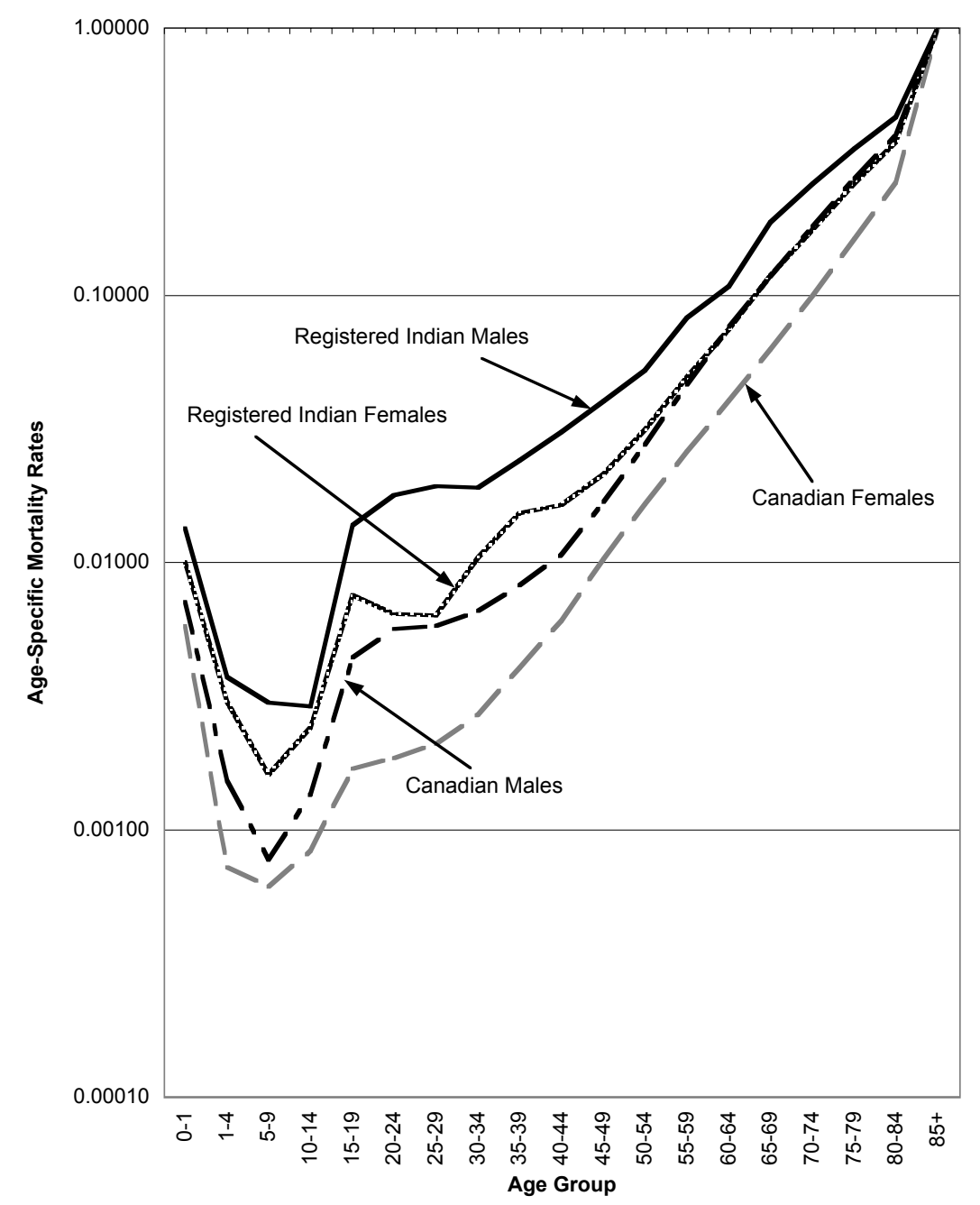




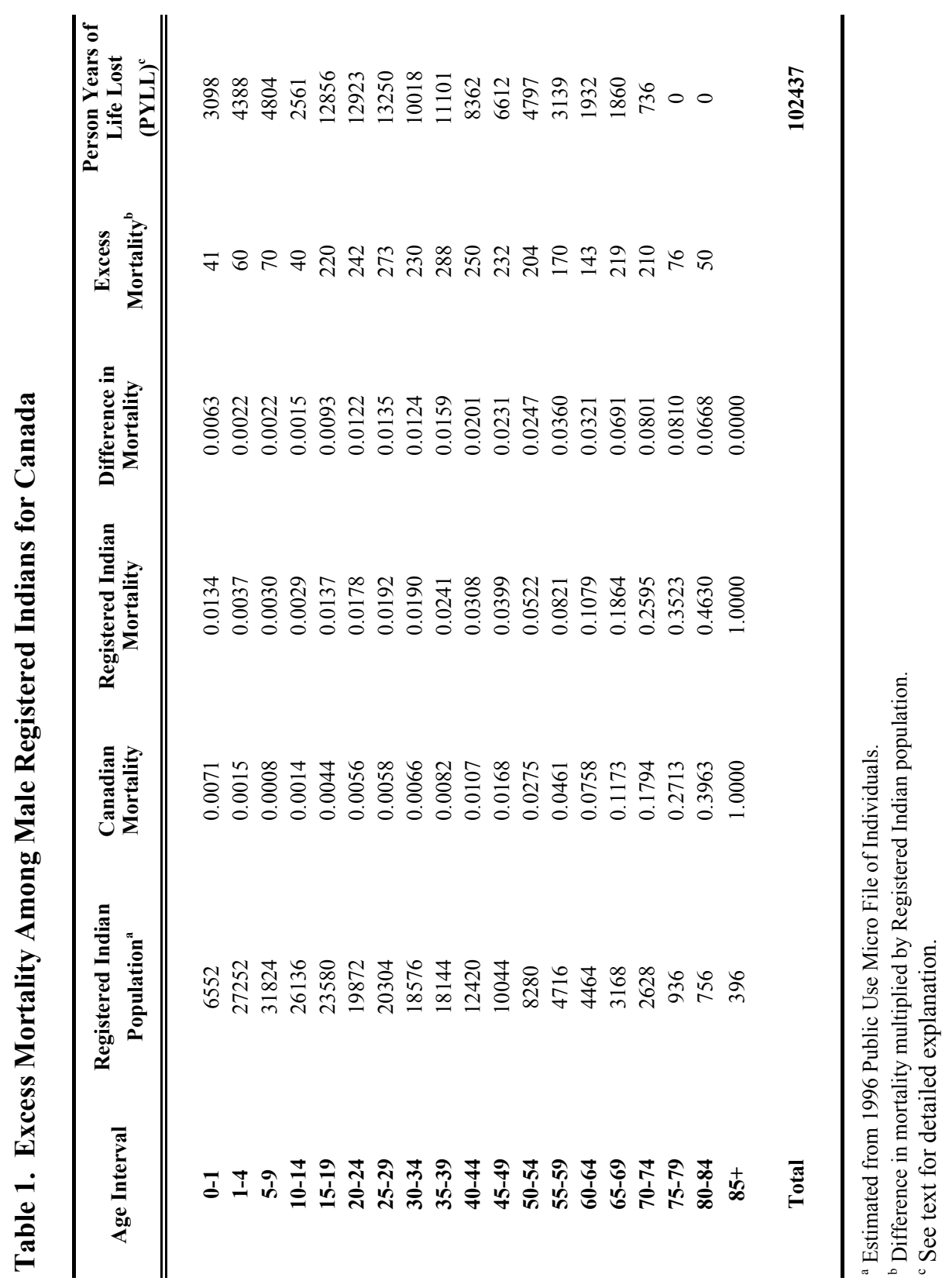


Paul S. Maxim, Jerry P. White, Stephen O. Gyimah and Daniel Beavon

Similar patterns hold for women. Again, in all age categories, Registered Indian women have higher rates of mortality than non-Aboriginal Canadian women. The differences in mortality also increase with age. For women, the total years of estimated lost life is 65,473 (Table 2).

\section{Lost Income}

Tables 3 and 4 provide estimates of potential earnings for males and females respectively. For males, the total value of lost (potential) life time income for males is almost a $\$ 1.2$ billion, while for females, the total value of lost (potential) income is $\$ 0.5$ billion (Table 4). In Tables 5 and 6 , the potential income and earnings lost are re-estimated using the earnings and incomes of all Canadians. The results suggest that the lost in income will be far greater if Registered Indians earn the same income as other Canadians.

\section{Additional social and private costs}

After a child is born, parents, other relatives and the broader community begin immediately to make investments. The feeding, clothing, and sheltering of children are a major expense as is education and healthcare. As children turn into young adults, they enter the labour market and over their productive years they "repay" the investment made in them. This repayment may be in the private sphere - as when one takes care of parents or invests in one's children - or in the public sphere through the payment of taxes. In a population where there are patterns of early mortality the opportunity to "repay" the investment is cut short.

We present here some rough estimates of the cost of raising children. We have limited our analysis to three areas: family expenses, which cover estimates of the private cost of a raising a child; public educational costs; and, the public costs associated with healthcare. No data exists identifying any differential cost associated with raising a young Aboriginal person as opposed to a non Aboriginal person. Consequently, this analysis makes the assumption that the average cost is uniform for all Canadians.

Family expenses: The cost of raising a child varies in Canada by province and by geography within provinces. Cost structures and income possibilities differ for rural populations and major urban populations. Calculating a basic average amount that a Canadian family might face is, however, possible. The Vanier Institute (2000) did such a study and concluded that boys cost $\$ 154,267$ and girls cost $\$ 153,458$ to raise from birth to age 18 years. ${ }^{6}$ We have averaged those values and use $\$ 153,863$ per child. 


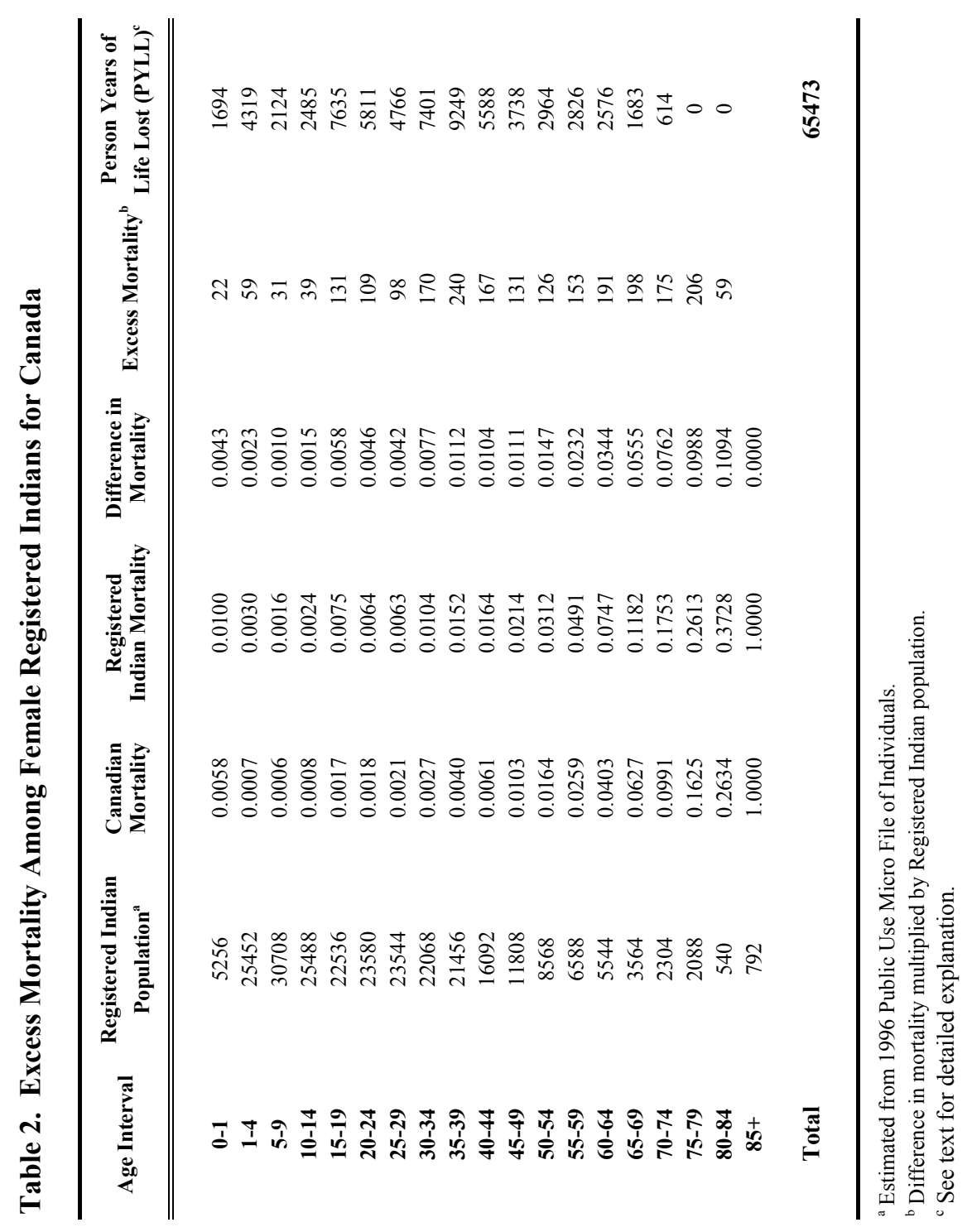




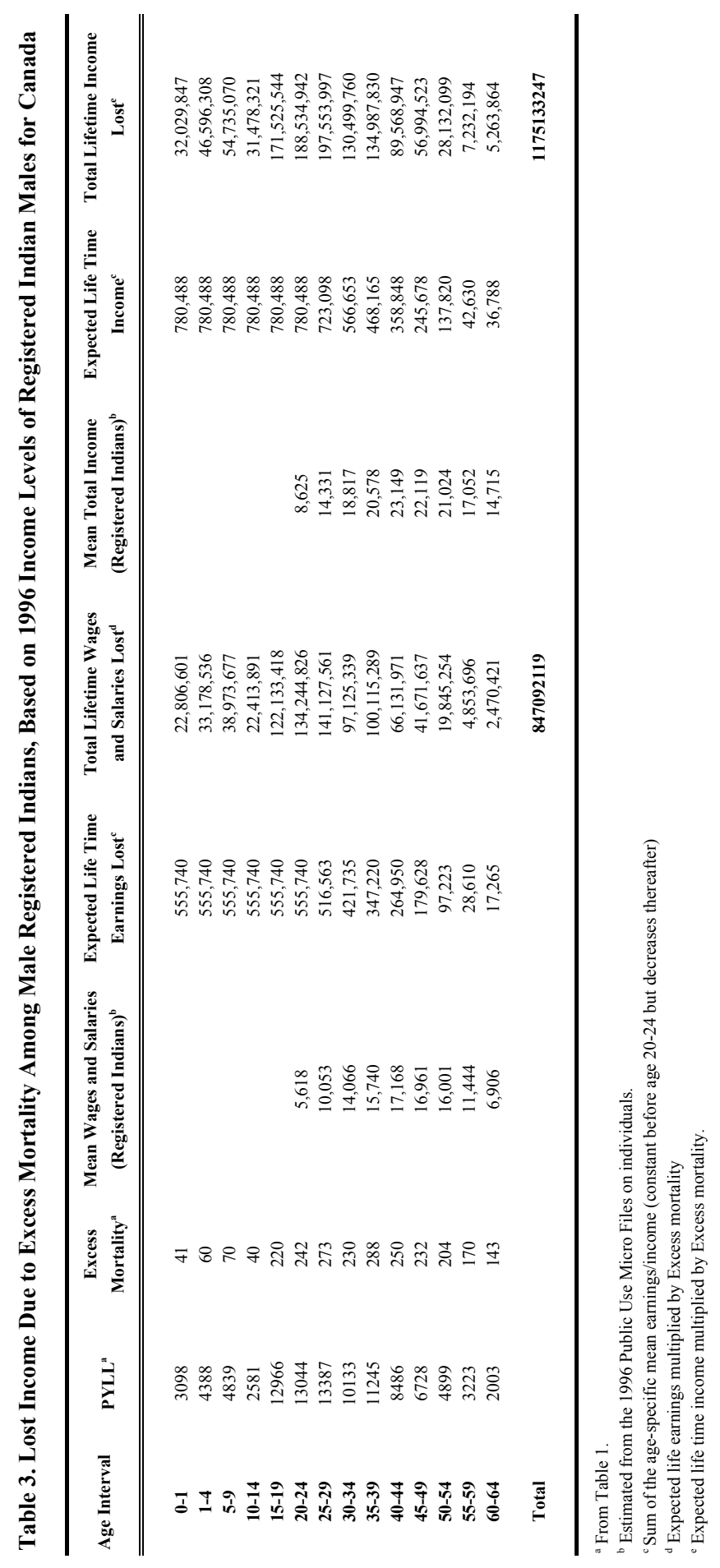




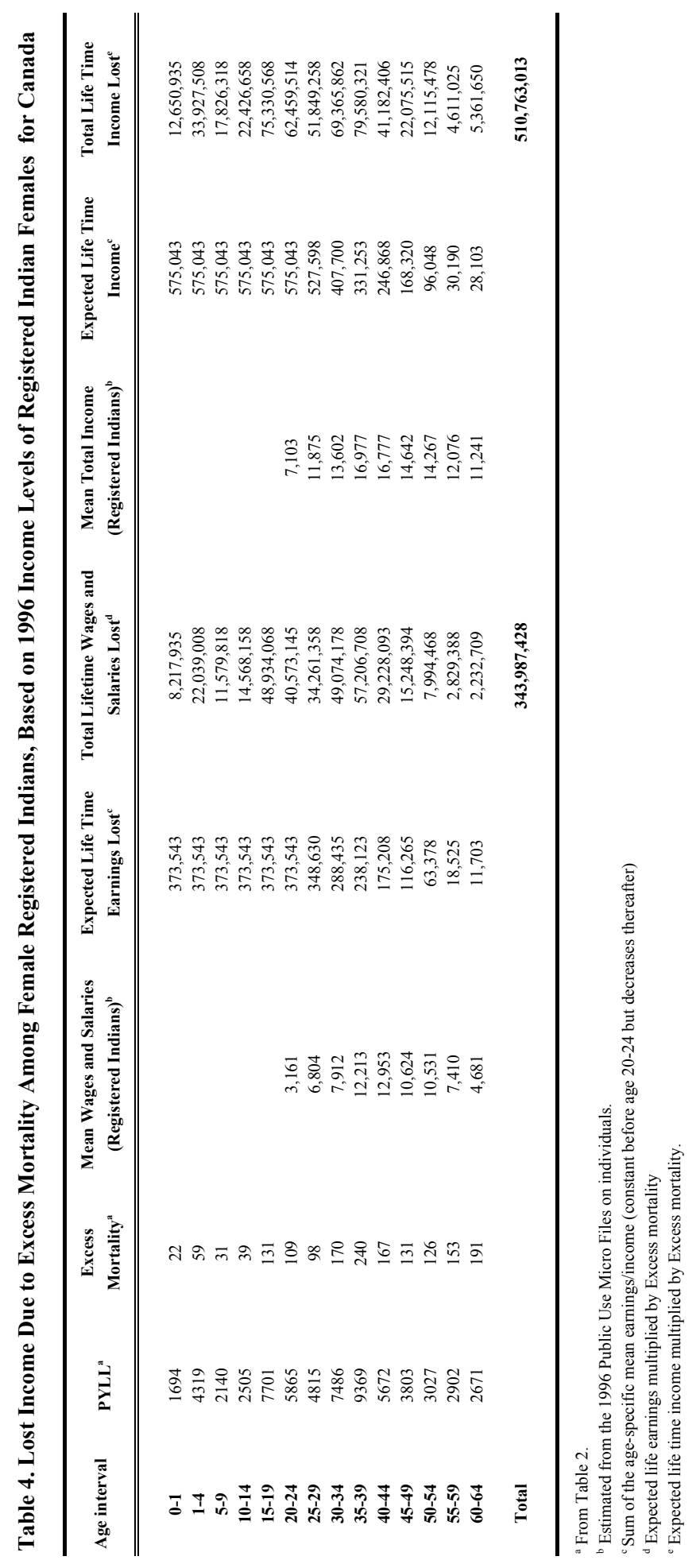




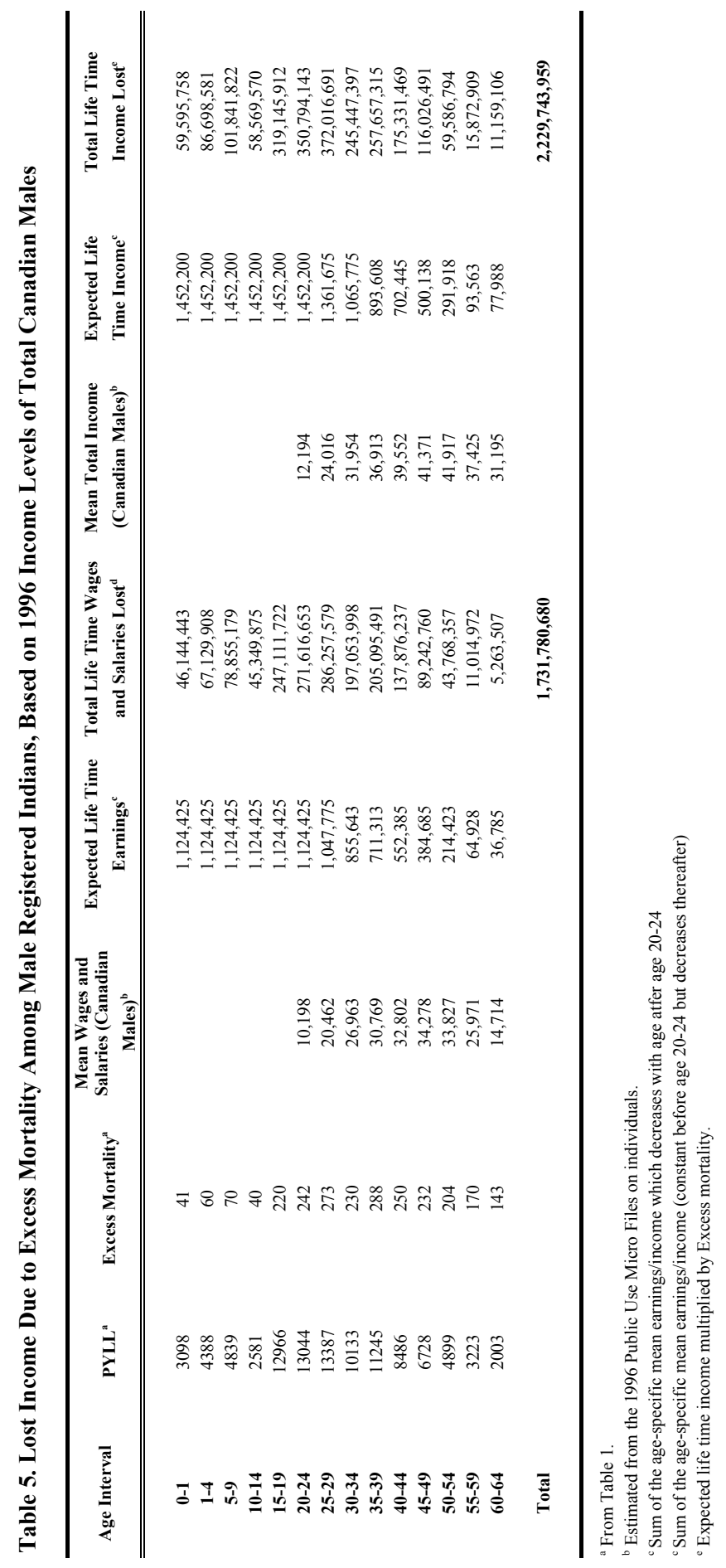


Education costs: Education has both a private and public component. The expense calculations for the family include the private costs of education for primary school and that covers all but four years of the private expenditure. We have no reliable way to calculate the private cost associated with secondary school attendance therefore we have excluded them and accept our overall estimate is low.

Educational expenses per student vary greatly in Canada across the provinces. Statistics Canada (1996) calculates the expenditure per student based the cost for elementary and secondary education, excluding adult education, divided by the full-time equivalent number of students enrolled in the elementary and secondary systems. Costs vary from $\$ 5,083$ per elementary student in Nova Scotia to $\$ 11,981$ in the Yukon Territory (Statistics Canada, 1996:36). We have taken the mean value of the provincial expenditure per full-time student that is $\$ 6768$. This would mean an expenditure or investment of $\$ 81,216$ from kindergarten through to grade 12 .

Healthcare: Healthcare costs also vary across the country. To estimate the costs we have to take a base year and calculate the average public expenditure of a defined set of services. We chose to use the sum of hospital, physicians and other professionals, drugs, capital investment and other direct health costs. This has been averaged for Canada and broken down by age-cohort (CIHI 2001). We have aggregated the data between 1 and 18 years of age. 7 Based on the CIHI study, we estimate the cost of healthcare for a young person between 0 and 18 years of age to be about $\$ 15,800$.

Aggregating these data, the cumulative expenditure or investment per child over a youth's life course is $\$ 253,865$. This represents a substantial investment in each person, and represents a sum that is in addition to potential earnings' loss in assessing PYLL. Using the data presented in Tables 3 and 4, calculating the approximate payback time for this investment is possible. Based on the mean wage and salary earnings for Aboriginal people, it would take Aboriginal males entering the labour market about 21.5 years to earn a quarter of a million dollars. It would take Aboriginal women slightly less than 29 years to earn a similar amount. If we use the average wage and salary earnings for all Canadians, the payback period reduces to about 14 years for men and 18.5 years for women.

As indicated, these are rough estimates. Taking into account could make further refinements other sources of income and by assessing "in kind" contributions such as when parents stay home to raise their children or care for other relatives. 8 The point to be made, however, is that the broader community shoulders a substantial burden when potentially productive young people are lost. 


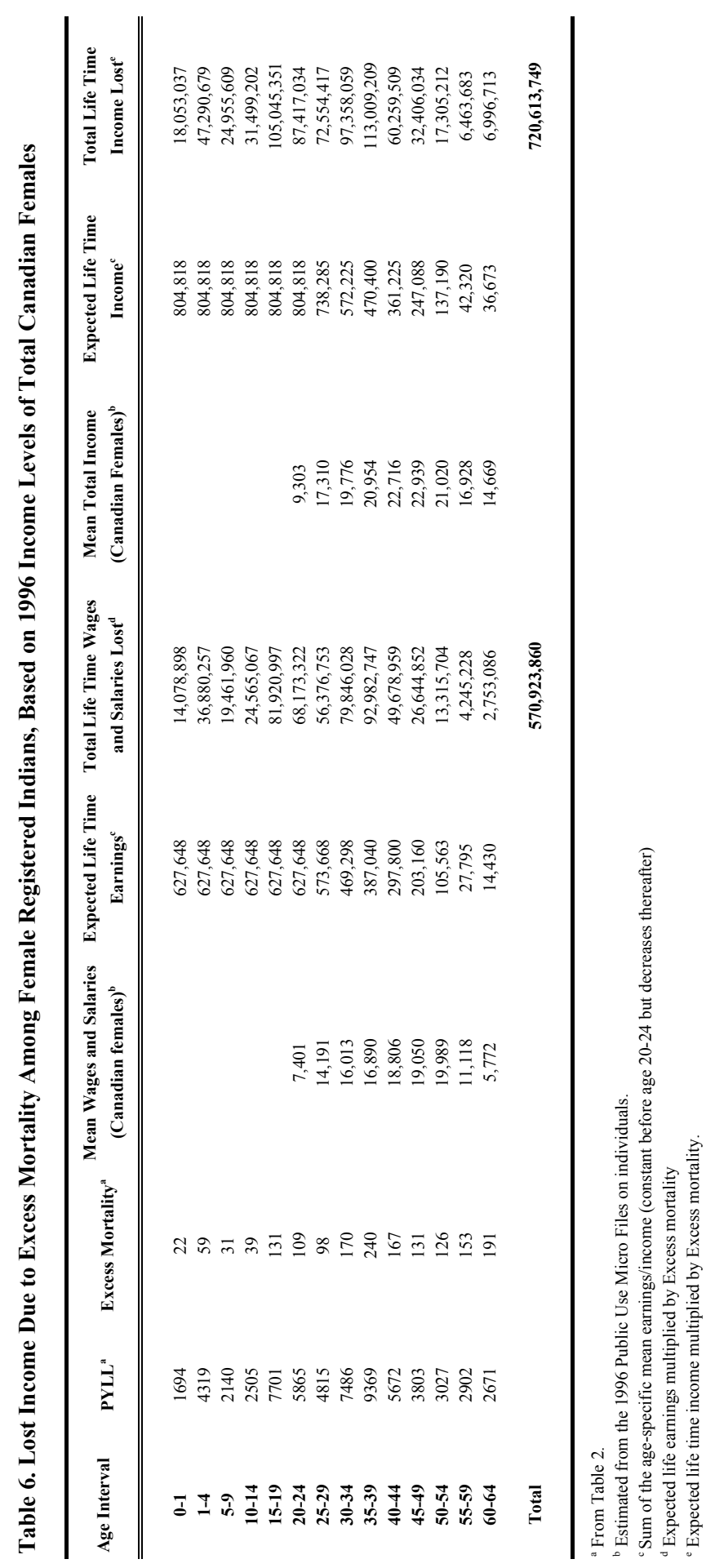




\section{Conclusion}

The results suggest the following: Registered Indians experience excess mortality in all age categories; excess mortality is greater for men in all age categories up to $70-74$; total person years of lost life is greater for men $(102,437)$ than for women $(65,473)$; the total number of years of lost life is estimated to be 167,910 ; and, the estimated income lost to excess mortality for persons under age 65 is $\$ 1.56$ billion.

Lost income is, of course, only one of many costs associated with excess mortality. In addition, there is a lost of the investments made in people in their early years. One may think of the youth life course as primarily a period of dependency. During this period, families, the community and the public make a great investment which people repay only after a considerable period of labour market involvement. Excess mortality also reduces the payback on this social cost and has to be considered as a loss to the society.

We have looked at this investment and the lost income because they are one of the easier set of costs to estimate. It provides an opportunity to appreciate the size of the difference that results from what the lay person may see as small differences in the mortality experience of two populations. The differences between Registered Indians and other Canadians are not small, but are best appreciated by totaling, as we have done here, the person years of lost life and the potential income and lost youth investment associated with those years.

We would argue that dealing with the root causes of excess mortality is important as both a social and economic cost to this situation exists. The earlier loss of life affects the demographics of the population by altering the age distributions. It certainly has an impact on the families who experience the loss. Beyond that, however, it has an impact on both the repayment of the childhood investment and the lost potential income.

Two sets of questions about excess mortality are of considerable interest, but beyond the scope of this paper other than to mention them and set them out for future research. The first set deals with the causes of excessive mortality and the second relates to the consequences of excessive mortality. The causes of excessive mortality are important for two major reasons. First, such factors as age clearly confound cause of death of death and whether death is sudden or follows a long period of illness. Younger people are more likely to die of violent causes than are older persons, and older persons are more likely to die after having experienced a lengthy illness. The current analysis and the estimates that it 
generates are based on the assumption that death is instantaneous which means not preceded by reduced income due to illness. As we learn more about the actual causes of death, refining these estimates will be possible.

Second, they have implications for the disruption to the lives of families and communities and different causes may require different interventions for dealing with consequences or preventing the excess mortality. While Registered Indians have higher rates of infectious diseases than other Canadians, it is not the rampant spread of such conditions that produce the large differences in excess mortality (Trovato 2001). Registered Indians have higher rates of violent death than other Canadians (e.g., homicide, suicide, deathly fire and other accidents) (Royal Commission on Aboriginal Peoples,1995; Mao et al . 1992; Sinclair 1998; Kirmayer 1998). They also have higher rates of deaths associated with the use of alcohol and other substances than the non Native population. Disproportionately the persons involved are male and younger. This means that First Nations communities are deprived of younger men at an earlier age than other Canadian communities. The importance of this, as with lost income, is that many of these communities are very small so the premature loss of even small number of persons can mean an appreciable loss to a community of, say, 2000 people.

That so many premature deaths are violent is frequently shocking to the community. Furthermore, death by suicide 9 often results in imitation where one suicide is followed by others and the community finds itself in the midst of a "suicide run"; in a few months the community may experience three, four or five suicides. Alcohol frequently fuels violence, which sometimes ends in death, and can leave a trail of broken relationships, spousal abuse and neglected or abused children taken into care as wards of the state.

Premature death also means that families are left incomplete: there are fewer adults to socialize the young, care for children, and contribute to family income. It reduces the number of role models and the amount of human capital in the community. We cannot tell from the data examined in this paper whether rates of excess mortality are correlated with levels of human capital; that must await another study.

With respect to income, we can see that premature death deprives First Nations families and communities substantial amount of potential income. Whatever multiplier effect that would have in reserve communities is also lost. The economic base of most First Nations communities is already precarious and economic development has been difficult and slow. The loss of income flows through families, in particular, and communities in general. The attendant loss of human capital reduces financial capacity and may reduce community 
development to a rate below what is possible if the mortality experience of Registered Indians mirrored that of the rest of the Canadian population.

\section{End Notes:}

1. The status of aboriginality is complex within the Canadian context. While we use the generic term "Aboriginal" people throughout this paper, the focus is on that subgroup legally known as "Status Indians." By way of explanation, most of Canada's aboriginal population living in the far North are of Inuit origin. Historically, these people were often referred to as "Eskimo," a term considered derogatory by the Inuit. Aboriginal peoples in the southern part of Canada were called "North American Indians" by the early European Settlers. "Indians" whose ancestors signed treaties with the government, are generally covered by the Indian Act and are legally considered to be "Registered" or "Status Indians." One may be of aboriginal ancestry but not have status under the Indian Act. Most often, this occurs through exogamy. Most Status Indians in Canada reside on reserves or what are now known as First Nations communities. Approximately three- quarters of a million people have status by being listed on the Indian Register.

2. There have been many studies that have attempted to develop theories and explanations of excess mortality. Most of the theories target the form and content of the socio-cultural contact of settler regimes with indigenous populations. The on-going marginalization as well as social and economic discrimination has created a lack of social cohesion and social problems that enhance mortality and morbidity (Boldt 1993; Trovado 2001). Recent work on social capital and its formation indicates that population outcomes are related to issues of community incoherence (Coleman 1990,1988; White, Maxim and Beavon 2003).

3. Statistics Canada (1995) Table 2: Detailed life table, Canada, 1990-1992.

4. We considered augmenting these data with estimates from other sources; however, obtaining reliable age-sex-specific counts to perform the augmentation was not possible within the time allocated for this study.

5. Specifically, the $\mathrm{q}_{\mathrm{x}}$ values from the Registered Indian and national life tables.

6. The study was conducted in Manitoba, Canada, based on the cost of living in that province. Education expenses associated with primary school were 
Paul S. Maxim, Jerry P. White, Stephen O. Gyimah and Daniel Beavon

included but not those for secondary school. There was some adjustments for the savings accrued for second and third children.

7. The data had been aggregated by age group and did not break cleanly at the year age 18 . We had to partition the $14 \mathrm{yr}$. to 44 yr. category. To do this we used a simple proportion.

8. This is particularly applicable to assessing stay-at-home spousal contributions. When a spouse stays at home they may register a zero income but are nonetheless making a contribution to the investment in children and in that sense participating in the "repayment" of the investment made in earlier periods.

9. The incidence of suicide for non Aboriginal persons in Canada is done 20/100,000 population per year. For Aboriginal Canadians it is at least $50 / 100,000$ population per year.

\section{References:}

Ammons, L. 1997. "Consequences of violence in the African American community in 1991," Western Journal of Black Studies, 21: 199-203.

Beavon, D and M. Cook. 2003. An Application of the United Nations Human Development Index to Registered Indians in Canada, 1996, in White, J.P., Paul Maxim and Dan Beavon, 2003 (forthcoming). Aboriginal Conditions: The Research Foundations of Public Policy. Vancouver: University of British Columbia Press.

Beer, V., B. Bisig and F. Gutzwiller, 1993. "Social Class Gradients in the Potential Life lost in Switzerland," Social Science and Medicine, 37: 1011-1018.

Bobet, E., 1989. Indian Mortality, in K. Thompson, Canadian Social Trends. Thompson Publishing.

Boldt, E. 1993. Surviving as Indians: The Challenge of Self Government. University of Toronto Press. 
Canadian Institute for Health Information (CIHI). 2001. Total Health Expenditure, by Province/Territory and Canada 1975-2000 - Current Dollars Table B.1.2. Canadian Institute for Health Information Electronic Data Services [www.cihi.ca/facts/nhex/nhex2000/table/B.1.2].

Clatworthy, S., J. Hull and N. Laughran 1995. Patterns of Employment, Unemployment and Poverty. Four Directions Consulting. Report to Royal Commission on Aboriginal People (1996): People to People Nation to Nation. Minister of Supply and Services Canada.

Fox, P., J. Gazzaniga, A. Karter, and Max, W. 1996. The Economic Costs of Cardiovascular Disease Mortality in California, 1991. Implications for Public Health Policies. Journal of Public Health Policy 17 (4): 442-459.

Frideres, J. 1998. Aboriginal Peoples in Canada $\left(5^{\text {th }}\right.$ ed.). Scarborough: Prentice-Hall.

Health Canada. 1996. Trend in First Nations Mortality, 1979-1993. Ottawa: First Nations and Inuit Health Programs Directorate.

Indian Affairs and Northern Development. 1997. Implications of First Nations Demography. Ottawa: Research and Analysis Directorate.

Indian Affairs and Northern Development.1998. Basic Departmental Data 1997. Departmental Statistics Division, Ottawa: Ministry of Public Works and Government Services.

Indian Affairs and Northern Development.1999a. A Second Diagnostic on the Health of First Nations and Inuit People in Canada. Ottawa.

Indian Affairs and Northern Development. 1999b. Indian Affairs and Northern Development and the Canadian Polar Commission 1999-2000 Estimates. Report Plans and Priorities. Ottawa.

Kirmayer, Laurence J. ,1998. Christopher Fletcher, Lucy J. Boothroyd. Suicide among the Inuit of Canada, in A.A. Leenaars (ed.) Suicide in Canada. Toronto: University of Toronto Press.

Mao, Y., Moloughney, B. Semenciw, R. M. and Morrison, H.I. 1992, "Indian Reserve and Registered Indian Mortality in Canada,".Canadian Journal of Public Health, 83 (5): 350-354. 
Paul S. Maxim, Jerry P. White, Stephen O. Gyimah and Daniel Beavon

Martinez-Schnell, B. and Waxweiler, R. 1989. "Increases in premature mortality due to homicide - United States 1968-1985," Violence and Victims, 4: 287-293.

McIsaac, S., and Wilkinson, R. 1997. "Income distribution and cause specific mortality," European Journal of Public Health, 7: 45-53.

Norris, M. J. Contemporary Demography of Aboriginal Peoples in Canada, in D. Long, O.P. Dichason (editors) Visions of the Heart : Canadian Aboriginal Issues, Toronto: Harcourt Brace., Pp. 179-237.

Organization for Economic Co-operation and Development. 1999. OECD Health Data 99 (CD- ROM)

Panush, N. and Peritz, E. 1996. "Potential demography: Another look," European Journal of Population, 12: 27-39.

Rose, H. (ed.) 1979. Lethal Aspects of Urban Violence, Lexington Books: Lexington MA.

Royal Commission on Aboriginal People. 1995. Choosing Life: Special report on Suicide Among Aboriginal People. Ottawa: Minister of Supply and Services Canada.

Sinclair,C.M.. 1998. Suicide in First Nations Peoples, in: A.A. Leenaars (ed.) Suicide in Canada. Toronto: University of Toronto Press.

Statistics Canada. 1995. Life Tables, Canada and the Provinces, 1990-1992. Ottawa: Supply and Services, Cat No. 84-537.

Statistics Canada. 1997. Births and Deaths, 1995. Health Statistics Division. Ottawa: Ministry of Industry.

Statistics Canada. 1996. A Statistical Portrait of Elementary and Secondary Education in Canada. Third edition. Ottawa: Ministry of Supply and Services.

Statistics Canada. 1998a. 1996 Census: Aboriginal data. The Daily, 13 January 1998.

Statistics Canada. 1998b. 1996 Census: Education, Mobility and Migration. The Daily 1998. 
Statistics Canada. 1998c. Deaths, 1996. The Daily, 16 April, 1998.

Statistics Canada. 2000. Population by Sex and Age. CANSIM, Matrix 6367. 25 May, 2001.

Trovato, F. 2001. "Aboriginal Mortality in Canada, The United States and New Zealand," Journal of Biosocial Science. Vol. 33. 67-86. Cambridge: Cambridge University Press.

The Vanier Institute of the Family. 2000. Profiling Canada's Families II. Ottawa: The Vanier Institute of the Family.

White, J.P. , Paul Maxim and Dan Beavon, 2003 (forthcoming). Aboriginal Conditions: The Research Foundations of Public Policy. Vancouver: University of British Columbia Press.

White, J.P., P. Maxim, P.C. Whitehead, and D. Beavon, 2000. Dispersion and Polarization of Income Among Aboriginal Canadians, Working Paper FN. 00-02. London, Ontario: Population Studies Centre, University of Western Ontario.

Whitehead, P. and M. Hayes. 1998. The Insanity of Alcohol: Social Problems in Canadian First Nations Communities. Toronto: New Scholars Press. 